\title{
Training the Mind to go Visiting
}

\author{
Christina Fredengren (1)
}

In the keynote my goal was to highlight some challenges in how to recognize human-animal relations in archaeology and to provide a selection of ideas and tools from new materialism and critical posthumanist feminism to raise questions on how the division into humanity and animality may have been produced and changed in the past. It was important to me to move both with and beyond recent strands of entanglement theory in archaeology. I felt there was a need to highlight the urgency of taking one step further, beyond the relativism of flat ontologies, to ask questions about how power differentials may have been at work in the past. This to interrogate who benefits and thrives in a particular temporally and spatially situated entanglement, and who carries the burden in particular spatiotemporal set-ups and processes. The tone I wanted to set was one of academic generosity, where one can share creative/critical thinking as well as pointers towards important literature and works that need to be brought into the discussion or to highlight shared concerns. These written keynotes have the potential to throw light on different areas of great importance to the subject and to work as nodes for bringing together reading and ideas to take forward in future research cooperation or in teaching. Furthermore, I would like to lift forward this field of more-than-human studies as one of archaeology's contributions to the emerging field of the Environmental Humanities.

I would like to thank my six commentators for their thoughtful and generous contributions to this endeavour and their lavish sharing of references

Department of Archaeology and Classical Studies, Stockholm University

christina.fredengren@arklab.su.se 
to their work and that of others. I will now both respond and also explain some of the ideas and thoughts highlighted in the replies and which need more attention. However, I will start to do this with a brief note on the term response-ability - a topic that many of our critical feminist posthumanist scholars have written about (Haraway 2008, 20I6; Despret 2013, 2015; Barad 2007), and which features togetherness in discussing what matters as well as the sharing and cooperation necessary in making something knowable and also the humbleness of not knowing and the joy of carrying out joint speculations.

In doing this I would like to share one of my favourite passages in Haraway (2016:130):

Hanna Arendt and Virgina Wolf both understood the high stakes of training the mind to go visiting, to venture off the beaten path to meet unexpected, nonnatal kin, and to strike up conversation, to pose and respond to interesting question, to propose together something unanticipated, to take up the unasked-for obligations of having met. This is what I call response-ability.

As a vote of thanks, I will try my best to meet you in this response - and to see where we together can venture off on known and unknown paths and perhaps strike further conversation. I will gather the response under a series of topic headings.

\section{Anthropocentrism in archaeology and heritage studies}

What does it mean to train the mind to go visiting in the practice of archaeology and in heritage studies? As I suggested in the keynote, it could be to pay close attention to how relations of the world fold out and change, to be curious about other ways in which situated worlds are brought into being, to bear witness to processes of violence and care (perhaps even violentcare), and to make each other capable and to co-create our learning in the field between past, present and emerging futures.

Adrienne Frie features our joint interests in working affirmatively with entanglement and taxonomies to discuss power formations in multi-species communities - where several archaeological analyses show both care and abuse of animals. Importantly Frei asks questions around what a nonanthropocentric multispecies archaeology might be like - and wonders 'can the archaeological project ever be non-anthropocentric?' (Frie 202I:35). My response is that I think there is a need to consider what anthropocentrism does in archaeology - and that there is room to explore what happens when anthropocentrism is questioned and the more-than-human is let in as the 
node around which we build understandings of the past - albeit where the figure of the human is questioned.

I would like to continue the discussion on this topic by elaborating on different aspects of anthropocentrism, here the three forms of perceptive, descriptive and normative anthropocentrism as discussed in environmental philosophy (Mylius 20I8). Possibly we could strike conversation on how and to what degree archaeology and perhaps also heritage studies work primarily on human sense data and perception as a perceptive anthropocentrism - and what ways there could be around this. Here I would like to draw on Eva Hayward's 20I0 paper that explores how the world can be perceived through the sensory organs of a different species. This underlines the importance of seeing how the world comes across through differently situated ways of perceiving, but also draws in the discussion on how human-animal bodies co-work. But I would also problematize what we mean by human sense data, as such data is rarely human alone, but comes about through the intra-action between human and environment and may be enhanced by the work of different apparatuses. Take the classical example of how wearing a pair of glasses formats sensory data, which then becomes more-thanhuman perception, or how a dog bark improves human noticing of guests.

We could move on to look whether scholarship in these subjects works with a descriptive anthropocentrism in so far as the interpretations evolve primarily around the human. This is also what Russell (202I:52) highlights:

often when we attempt to put humans and other animals on the same plane, humans remain implicitly centered. We still mostly consider other species only in relation to their interactions with humans, and it concerns me that the more implicit the centering of humans, the less we acknowledge the power relations that Fredengren insists we must confront.

We both have a problem with the lack of power discussions in the so called flat-ontologies. The Baradian take opens up towards analyzing both relatedness and power formations in our discipline as in others. Archaeology can be about other-than-humans - one example is the recently defended $\mathrm{PhD}$ thesis of Hans Ahlgren (202I) that carefully traces out several agencies that could have caused extinction and extirpation of species as hare, elk or seal, where human action is only one factor among many that brought about change to the future of these animals.

Further, one might want to discuss normative anthropocentrism - and to look at archaeological material to identify activities and technologies in the past that feed into a build-up of human supremacy that produced the human and the non-human as categories set apart. With Adrienne Frei (202I:36) I would like to further explore how 'power differentials are cre- 
ated, enforced, and justified in past societies, as well as how these structures changed over time'.

Andy Jones (202I) expands on the keynote by reminding us of the history of ideas on this topic in archaeology. As he points out, entanglement theory has a considerable background in archaeology. Particularly important to highlight is the difference between Latourian ANT and Baradian approaches, where some uses in archaeology (such as Hodder 20I6) work from entanglement theory and then re-center the human being. We both would like to expand Hodder's work with Baradian thinking and continue to question anthropocentrism in its different versions.

\section{More-than-human}

Richard Bradley's (202I) contribution highlights several examples of variation in processes of how and which bodies came to be deposited in wetlands. I agree - there are several temporally and situated processes that produce the phenomena of body parts deposited in bogs. Bradley has problems with terms such as more-than-human or onto-ethic-epistemologies and here I would like to make some clarifications. These are not of my own making but are quite often used in Environmental Humanities and in discussing human-animal relations in critical posthumanism (e.g. Jaque et al. eds. 2020). Many posthumanist thinkers are quite hard reads and often use neologisms, which has been criticised. However, one can see this a way to work in-between categories to get out of taxonomic folds: a way to point out that there is something materialising to be analysed in-between common concepts. Kristina Jennbert (2021:44) helpfully outlines: 'with the terminology of humans, non-human animals, more-than-humans, there is a possibility to embrace all kinds of beings in the world and the boundary crossings in the time-setting and thus to work towards a non-anthropocentric ontology'. Artistic research can work in similar ways to move beyond restrictions of written word and text, and as addressed in Kristin Oma Armstrong's (202I) paper, collaborations with artistic researchers can be a productive entry point for articulating relationships that otherwise might go un-noticed.

To engage the more-than-human in archaeological research is a way of questioning that the division into nature and culture is valid for all times and to start to analyze the historical processes when such binaries came apart and were active. It works to challenge and critique human exceptionalism written into archaeological narratives. Human exceptionalism has been a major lens during an era of research that can be called high humanism. This is an approach that researches subjectivities (for example of those bodies we call human or animal) as complex and nomadic and differenti- 
ating, that is, in process (Braidotti 20I3:49-50). Humans are always more than human as they come about through situated relations with the rest of the world: humans are in nature and nature is in the human. But the term also serves to question the animal as a pure natural category: they as well become subjectivities in relation to technology, climate change or environmental pollution. As Tsing (2OI3) points out 'living beings other than humans are fully social - with or without humans'. More-than-human sociality deals with both - or what can be captured in a 'both-and' - thereby transgressing ordinary hybridity.

To investigate the more-than-human is to take a special interest in the phenomena that occur when relations are set up and how such relations change everyone involved. This is a rejection of the individual as a classical humanist subject, as it opens space for tracing how bodies are in constant interchanges with others and the environment, and are in process to become something else. I have exemplified such exchanges in discussions about archaeological isotope analysis that show how the human body is always more-than-human and where the body incorporates substance from the landscape it lives in. The body comes about as a relational entity in flux, as an intrasubjectivity, and as more-than-human. A landscape imprints, strikes up relationships with and makes a situated body come into being and change (Fredengren 20I3, 20I8b). Yet another thread could be to start to identify the archaeological evidence for how humans and animals may have worked symbiotically for each other's benefit and through mutual care.

Joanna Brück (2019:224-225) writes about the Bronze Age self, that it was composed through relations with things, where the encounter with metalworking and the combination of materials made a difference. She mentions how relationships with places contributed to constituting a person of 'substances and elements flowing in and out of the wider social landscape'. This reasoning suggests that some people during the Bronze Age can be regarded as extended by things and places: they were more-than-human persons as they stretched outside their bodily bounds. Further, ancient rivers and wetlands can be acknowledged as subjectivities that have their personhood extended by depositions of goods and bodies: they can be analysed as more-than-human entities (Fredengren 20I8a) which places them more centrally in the analysis.

\section{Onto-ethic-epistemologies}

Kristina Jennbert's comment emphasizes that our present-day situatedness as archaeologists shapes the questions we pose and the theoretical tools we use. She gives several examples from Scandinavian material that point 
towards changing relationships with animals over time as seen in archaeological, osteological and textual sources. Together we are interested in exploring how animal agency can be written back into history and how humanity and animality are produced. We share an interest in philosophical questions and the existential in archaeology. With this background I would like to go into what is meant by the Baradian onto-ethic-epistemological reasoning, as it grounds ethical reasoning that goes beyond the calculus of the individual. This adds to how one can understand the ethical situatedness of archaeological practices and interpretations of today. The ontoethic-epistemological standpoint of Barad is a claim that being, valuing and knowing a phenomenon are interconnected. We are a part of the nature that we are trying to understand, not above it.

This is connected to another way of regarding subjectivity. Rather poetically, Barad (2007:393) writes 'not only subjects but also objects are permeated through and through with their entangled kin. The other is not just in one's skin, but in one's bones, in one's belly, in one's heart, in one's nucleus, in one's past and future'. Archaeological work brings the past about as knotted phenomena of what exists, through agencies and apparatuses of observation - and this has ethical implications. There is a call to act responsibly while making the agential cuts that make sense of our materials and where we bring a particular version of the past into the world, while other parts are not articulated and acknowledged to the same extent. However, this does not mean that the 'human' archaeologist is responsible for all the differentiation that goes on in the world. There are several morethan-human processes that bring about the past as it comes to the archaeological attention.

I agree with Kristina Jennbert (2O2I:46) that 'archaeology needs to explore threats in our contemporary society". Furthermore, Jennbert writes 'From a more hopeful perspective, a better understanding of alternative configurations of power in past societies may provide inspiration for alternative, more ethical distributions of power in our own multispecies communities". I agree with this and the power perspective is important to identify both benevolent and malevolent forces in how such multispecies existences come into play and change.

\section{Werevolves, Monsters and Unicorns}

I appreciate László Bartosiewicz's humorous and creative response that engages full-heartedly with the theories and materials presented in the keynote. He touches on the troubles of applying Linnean or veterinary taxonomic divisions onto the osteological material, which also resonate with 
Russel's contribution, and sees productive uses of the topic of killeability. Bartosiewicz also reminded me of earlier efforts at developing relational taxonomies, such as Zedeño (2009) that suggested alternative approaches for example through specific situated indigenous Native American knowledge systems. There it was a question of how to capture 'animate' objects in better ways in archaeology, but the question at hand here also extends into how humanity and animality are produced over time for example through practices and/or access to food, shelter and care. And further, to explore what lives exists in-between obvious binaries.

Bartosiewicz's comment contributes to a joint archaeological bestiary of unicorns, werewolves or monsters, and populates the theories with flesh and bone. It references how transcendental more-than-human beings were a reality in the past. This is a question of ontology - as in how the world existed. The comment brings to our attention burials where a human skeleton was composed with a sheep-head, but also animal remains that might have played a role in shamanistic trans-species shape shifting. Furthermore, it highlights how the study of bone manufacturing, paleopathology and in particular zoonoses can be ways of studying human-animal relations - but also other monstrosities that come about through virulent meetings not only now in the present but also in the past. A productive shift could be to check in with what has been written in the field of monster studies (e.g. Cohen 1996). Monsters can be invited in to academic analysis as they carry out both regenerative and subversive work (Haraway 1994). This suggests there are ways forward from working with representations of privileged voices, to the articulation of connectivities of neglected others, that otherwise risk falling outside normalized perceptual frames of recognition and representation.

What I tried to lift in the keynote and have discussed here is that there is no such thing as species autonomy: we are all in that respect multi-species monsters. Bodies in past, present and emerging futures are incongruous and contain lesser known parts. They are collections of several others of different temporal depth. Every creature lives through striking company with others, as feral mergers of technology, nature, culture and the like: we are all symbionts and ecologically connected throughout. In the book Arts of Living on a Damaged Planet (Tsing et al. 20I7) the figure of the monster has been a lead theme. The monstrous has several aspects that can assist us in developing unconventional thinking, which is needed in the environmentally challenged times we live in. First of all, we are all monstrous in some extent, exceeding whatever identity labels that have been pressed on us or that we work from. As archaeologists we are, as Armstrong Oma writes, grappling with understanding multispecies entanglement, sometimes from the back-seats, but we can try our best to work creatively to articulate those 
relationships that are at work yet slightly hidden from view. The monstrous are then deviants - existing at the borders of discourses - but also hold the potential to aid in catching multiple differences in the analysis. From this position one can also train one's mind to go visiting and to use archaeology and speculation to stretch the imagination towards other ways of making the world in environmentally challenged times.

\section{Power, carework \& the intra-generational}

Both I and Kristin Armstrong Oma have an interest in investigating multispecies care. In the words of feminist ethicist Joan Tronto (I993:I03), care defines 'a species activity that includes everything that we do to maintain, continue and repair our 'world' so that we can live in it as well as possible'. This means that it is not only humans that exercise care towards animals, but opens up for care as a multispecies activity. There is a need to further studies of archaeologies of care - or lack of care - with more-than-human allies.

Furthermore, to return to the beginning and the question of how to 'meet unexpected, non-natal kin, and to strike up conversation' we may want to probe a bit into the question of ancestry and kin. In the project Checking in with Deep Time (Fredengren \& Åsberg 2020) we work with a Baradian intra-generational method to investigate a multispecies 'coconstitutive togetherness and conviviality over time. This has bearings for how to build a more inclusive notion of justice and care between generations and to develop a more-than-human ethics of generations entangled with each other in intricate and situated ways. Furthermore, it also makes me curious to investigate further how non-natal kin might have been articulated in the archaeological material and to investigate and speculate in if and how multi-species ancestry has been acknowledged in the past.

Speaking with Haraway (2008:19), to respond is 'to have courteous regard for, to esteem: all of this is tied to polite greeting'. I would like highlight how we have been co-producing this piece of work and how our writings have made each other capable of addressing past, present and emerging futures in new ways.

\section{References}

Ahlgren, H. 2021. Prehistoric Human Impact on wild Mammalian Populations in Scandinavia. Theses and Papers in Scientific Archaeology 21. Stockholm: Stockholm University.

Armstrong Oma, K. 202 I. The View from the Cheap Seats: An Archaeologist Grappling with Multispecies Entanglements. Current Swedish Archaeology. Vol. 29 pp. $72-77$. 
Barad, K. 2007. Meeting the Universe halfways. Durham: Duke University Press.

Bartosiewicz, L. 202 I. Herding Cats. Current Swedish Archaeology. Vol. 29 pp. 56-7I.

Bradley, R. 202I. More Than. Current Swedish Archaeology. Vol. 29 pp. 48-5I.

Braidotti, R. 20I3. The Posthuman. Cambridge: Polity Press.

Brück, J. 20I9. Personifying Prehistory: Relational Ontologies in Bronze Age Britain and Ireland. Oxford: Oxford University Press.

Cohen, J.J. I996. Monster Culture (Seven Theses). In: Cohen, J.J. (ed.), Monster Theory, pp. 3-25. Minneapolis: University of Minnesota Press.

Despret, V. 20I3. From Secret Agents to Interagency. History and Theory. Vol. 52 pp. 29-44.

Despret, V. 2015. Why 'I Had not Read Derrida': Often Too Close, Always Too Far Away. In: Mackenzie, L. \& Posthumus, S. (eds), French Thinking about Animals, pp. 9I-IO4. Michigan: Michigan State University Press.

Fredengren, C. 20I3. Posthumanism, the Transcorporeal and Biomolecular Archaeology. Current Swedish Archaeology. Vol. 2I pp. 53-7I.

Fredengren, C. 20I8a. Personhood of Waters: Depositions of Bodies and Things in Water Contexts as a Way of Observing Agential Relationships. Current Swedish Archaeology. Vol. 26 pp. 219-245.

Fredengren, C. 20I8b. Archaeological Posthumanities: Feminist Re-invention of Humanities, Science and Material Pasts. In: Braidotti, R. \& Åsberg, C. (eds), A Feminist Companion to the Posthumanities. pp. I29-I40. New York: Springer.

Fredengren, C. \& Åsberg, C. 2020 . Checking in with Deep Time. In: Harrison, R. \& Sterling, C. (eds), Deterritorializing the Future: Heritage in, of and after the Anthropocene, pp. 56-95. London: Open Humanities Press.

Frei, A.C. 2021. Multispecies Futures. Current Swedish Archaeology. Vol. 29 pp. 34-37.

Haraway, D. 1994. The Promise of Monster: A Regenerative Politics for Inappropriate/d Others. In: Grossberg, L., Nelson, C. \& Treichler, P. (eds), Cultural Studies, pp. 295337. London: Routledge.

Haraway, D. 2008. When Species Meet. Minnesota: University of Minnesota Press.

Haraway, D. 20I6. Staying with the Trouble: Making Kin in the Chthulucene. Durham and London: Duke University Press.

Hayward, E. 20Io. Fingereyes: Impressions of Cup Corals. Cultural Anthropology. Vol. 25(4) pp. 577-599.

Hodder, I. 20I6. Studies in Human-thing Entanglement. www.ian-hodder.com/books/ studies-human-thing-entanglement. [Accessed 2I June 202I].

Jaque, A., Otero Verzier, M. \& Pietroiusti, L. (eds). 2020. The More-than-Human. Rotterdam: Het Nieuwe Instituut.

Jennbert, K. 202 I. Post-Humanistic Approaches in Archaeology. Current Swedish Archaeology. Vol. 29 pp. 43-47.

Jones, A.M. 202I. Disentangling Entanglement: Archaeological Encounters with the Concept of Entanglement. Current Swedish Archaeology. Vol. 29 pp. 38-42.

Mylius, B. 2018. Three Types of Anthropocentrism. Environmental Philosophy. Vol. I5(2) pp. I59-I94.

Russell, N. 202r. Power and Othering. Current Swedish Archaeology. Vol. 29 pp. 52-55.

Tsing, A. 20I3. More-than-Human Sociality... A Call for Critical Description. In: Hastrup, K. (ed.), Anthropology and Nature, pp. 27-42. Hoboken: Taylor and Francis. 
Tsing, A., Swanson, H., Gan, E. \& Bubandt, N. 2017. Arts of Living on a Damage Planet: Monsters. Minneapolis: Minnesota University Press.

Tronto, J. I993. Moral Boundaries: A Political Argument for an Ethics of Care. New York: Routledge.

Zedeño, M.N. 2009. Animating by Association: Index Objects and Relational Taxonomies. Cambridge Archaeological Journal. Vol. I9(3) pp. 407-4I7. 